\title{
Theoretical Method of Strain Rate for RC Beam with Flexible Supports Under Blast Loading
}

\author{
Wanxiang Chen ${ }^{\mathrm{a}, \mathrm{b}}$, Meng Jiang ${ }^{\mathrm{a},{ }^{*}}$, Zhikun Guo and Wenguang Liang ${ }^{\mathrm{c}}$ \\ ${ }^{a}$ State Key Laboratory of Disaster Prevention \& Mitigation of Explosion \& Impact, PLA University of Science and \\ Technology, China \\ ${ }^{b}$ State Key Laboratory for GeoMechanics and Deep Underground Engineering, China University of Mining and Tech- \\ nology, China \\ ${ }^{c}$ College of Business Administration, South China University of Technology, China
}

\begin{abstract}
Strain rate is a vital factor for the design of a RC (Reinforced Concrete) member under blast loading. At present, it is not scientific and cut down the believability to assume the strain rate is a constant or to take the loading rate instead of the strain rate. In this paper, an analytical model of RC beams with flexible supports is presented, in which the elasticity, damping, and lumped mass of flexible support are taken into account. Theoretical method of strain rate for RC beam with flexible supports under blast loading is developed based on Euler-Bernoulli beams. It is indicated that the maximal values of strain rate are increased as the blast impulses and the overpressures increased, but the loading rates have not obvious influences on the strain rates. The maximal values and the vibration frequencies of strain rate are increased as support stiffness increased. The maximal values of strain rate are decreased as support damping increased, and the attenuation values of strain rate are accelerated. Calculations show that it will result in an overestimation of DIF (Dynamic Increase Factor) to take the loading rate instead of the strain rate.
\end{abstract}

Keywords: Blast loading, dynamic response, flexible supports, reinforced concrete beam, strain rate.

\section{INTRODUCTION}

Concrete and steel are both sensitive to strain rate (strain in per unit time), and the strength, ductility and failure mode will be changed under high loading rate. It is significant to investigate into the strain rate effects for the design and checking for a reinforced concrete member under blast loading.

In recent years, the blast-resistances of various buildings and structures have caused peoples' attentions all over the world [1]. To improve the blast-resistances of beam/slab members in protective engineering, some new structures including members with flexible supports are developed except for improving the material properties. The support with its stiffness is comparable to the stiffness of member itself is usually be simplified to elastic support [2-4]. In addition, the damping effects must be considered if the energy dissipations of support cannot be neglected. Above movable supports with elastic and damping characteristics are called flexible boundaries [5-7].

At present, the failure mechanism of reinforced concrete structures under rapid loading is still not clear. It was supposed that the dynamic failure modes could be derived by the static failure modes by taking strain rate effects into account, and the values of strain rate are usually equal to the loading rate $[8,9]$. It is indicated by rapid loading tests of

\footnotetext{
*Address correspondence to this author at the State Key Laboratory of Disaster Prevention \& Mitigation of Explosion \& Impact, PLA University of Science and Technology, China; Tel: +86-13913893169;

E-mail: cwx_0806@sohu.com
}

concrete beam that the load-deflection curves are similar to that of under static loading, but the ultimate bearing capacities significantly improved. The increased values of bearing capacity mainly depend on the material strengths, but the values of deformation and ductility are similar to that of under static loading. Therefore, the analytical methods of RC (reinforced concrete) beam under static loading are usually applied to the blast-resistance designs by only introducing a constant DIF (Dynamic Increase Factor) [10]. Obviously, it is not scientific and cut down the believability to assume the strain rate is a constant or to take the loading rate instead of the strain rate for RC beams with flexible under blast loading. In this paper, the influences of loading characteristics and supporting condition on the DIF of concrete and steel for $\mathrm{RC}$ beams with flexible supports are analyzed.

\section{DYNAMIC RESPONSES}

Dynamic responses of non-deep RC beam (i.e. high/span $\leq 0.25$ ) with flexible supports under blast loading are analyzed based on Euler-Bernoulli beams. The action times of blast loads are very short, thus the blast loads are usually simplified to ideal triangular load [11].

$$
p(t)=p f(t)
$$

where, $p$ is the overpressure of blast load. $f(t)=\left(1-t / t_{d}\right)$ is the characteristic function of blast load, and $t_{d}$ is the positive action time. 


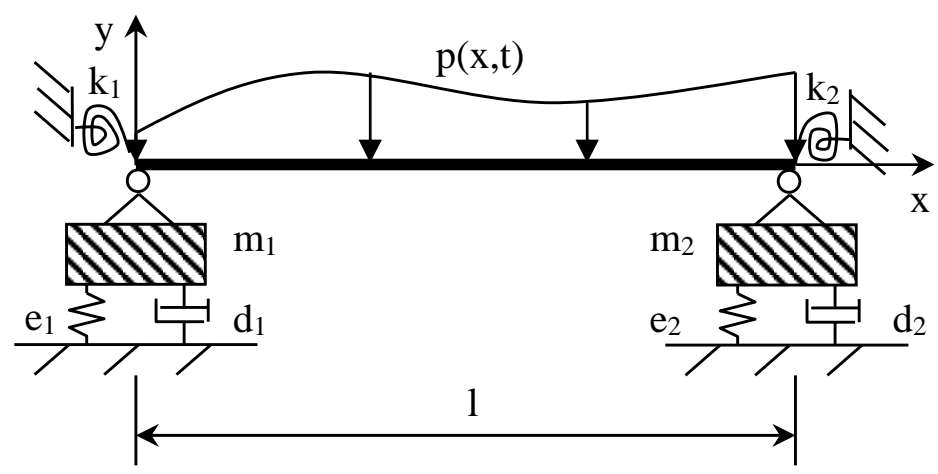

Fig. (1). Analytical model for beam with flexible supports.

As shown in Fig. (1), a RC beam with flexible supports is analyzed. The span is $l$, and the mass in per unit length is $m$. The elastic coefficient of support is $e$, and the damping coefficient is $d$, and the lumped mass is $m_{s}$. The response function of displacement is given below.

$y(x, t)=u(t)+\sum_{i=1}^{\infty} w_{i}(x) T_{i}(t)$

where, $u(t)$ is the rigid displacement due to compression of support, $w_{i}(x)$ is the shape function for $i$-order corresponding to $p_{\max }=1, T_{i}(t)$ is the time-history function for $i$ order.

The vibration equation of $\mathrm{RC}$ beam under blast loading is

$B \frac{\partial^{4} y(x, t)}{\partial x^{4}}+m \frac{\partial^{2} y(x, t)}{\partial t^{2}}=p(t)$

According to Ref. [12], a formula of bending stiffness for $\mathrm{RC}$ beam in normal case is

$$
B=\frac{E_{s} E_{c} h_{0}^{2}}{1.15 \psi+0.2+6 \alpha_{E} \rho_{s}}
$$

where, $E_{c}, E_{s}$ is the elastic modulus of concrete and steel, respectively. $h_{0}$ is the effective height of section, $\psi$ is nonuniformity coefficient of tensile steel strain, $\alpha_{E}=E_{s} / E_{c}$, $\rho_{s}$ is the reinforcement ratio.

The dynamic reaction at either end of the beam is

$R=e u(t)+d \dot{u}(t)$

where, $e=E_{s}^{\prime} A_{\phi} /(2 D)$ is the elastic coefficient of support, $d=\rho c_{p} A_{\phi}$ is the damping coefficient of support, $E_{s}^{\prime}$ is the compressive modulus, $c_{p}$ is the velocity of P-wave, $D$ is the height of support, $\rho$ is the material density, $A_{\phi}$ is the bottom area of support.

Since that the shape function $w_{i}(x)$ is approximate, on both sides of the Eq.(3) are not equal. Then the Eq.(6) is obtained by weighted residual method.

$$
\begin{aligned}
& \int_{0}^{l}\left[B \sum_{i=1}^{\infty} \frac{d^{4} w_{i}(x)}{d x^{4}} T_{i}(t)+m \frac{d^{2} u(t)}{d t^{2}}+m \sum_{i=1}^{\infty} \frac{d^{2} T_{i}(t)}{d t^{2}} w_{i}(x)-p(t)\right] \\
& w_{j}(x) d x=0(j=1,2, \cdots)
\end{aligned}
$$

According to the orthogonality between the main modes, i.e. $\int_{0}^{l} w_{i}(x) w_{j}(x)=0(i \neq j)$. The Eq.(6) can be further simplified.

$$
\begin{aligned}
& B T_{i}(t) \int_{0}^{l}\left[w_{i}^{\prime \prime}(x)\right]^{2} d x+m \int_{0}^{l} \ddot{u}(t) w_{i}(x) d x+m \ddot{T}_{i}(t) \int_{0}^{l} w_{i}^{2}(x) d x= \\
& p f(t) \int_{0}^{l} w_{i}(x) d x
\end{aligned}
$$

The Eq. (7) can be simplified to following equation based on Galerkin method.

$\ddot{T}_{i}(t)+\omega_{i}^{2} T_{i}(t)+A \ddot{u}(t)=\omega_{i}^{2} p f(t)$

where, $\omega_{i}^{2}=\frac{B \int_{0}^{l}\left[w_{i}^{\prime \prime}(x)\right]^{2} d x}{m \int_{0}^{l} w_{i}^{2}(x) d x}$ is the vibration frequency corre-

sponding to vibration mode $w_{i}(x)$, and $A=\frac{\int_{0}^{l} w_{i}(x) d x}{\int_{0}^{l} w_{i}^{2}(x) d x}$.

For both end of RC beam, there are

$m_{s} \ddot{u}(t)+R+Q(t)=0$

where, $Q(t)=-B \sum_{i=1}^{\infty} w_{i}^{\prime \prime}(0) T_{i}(t)=-B \sum_{i=1}^{\infty} w_{i}^{\prime \prime}(l) T_{i}(t)$.

Only the first vibration mode is usually considered for dynamic response of structure under blast loading [13]. Combining Eq. (8) and Eq. (9), the following equations are obtained.

$$
\left\{\begin{array}{l}
\ddot{T}_{1}(t)+\omega_{1}^{2} T_{1}(t)+A \ddot{u}(t)=\omega_{1}^{2} p f(t) \\
B w_{1}^{\prime \prime}(l) T_{1}(t)-m_{s} \ddot{u}(t)-d \dot{u}(t)-e u(t)
\end{array}\right.
$$


The initial conditions of Eqs. (10) at $t=0$ are given as

$T_{1}=0, \dot{T}_{1}=0, u=0, \dot{u}=0$

The Eqs. (10) at free vibration stage can be obtained by assuming that $f(t)=0$, and the initial conditions can be determined by the continuity of blast ending and free vibration starting.

\section{THEORETICAL ANALYSIS OF STRAIN RATE}

The cracks of RC members can be observed before global deformation, and the stage before longitudinal steel reaches its yield stress is considered to be quasi-elastic stage [14]. The plastic strains when members failed are quite small because that the action time of blast loading is short enough and the members are always too late to deform fully, it is assumed that the RC beam still satisfy the plane section hypothesis before failure [7]. The rotation angles of arbitrary cross section of RC beams at any time is

$\chi(x, t)=w_{1}^{\prime \prime}(x) T_{1}(t)$

The equation of first-order vibration mode for RC beam with simple supports under blast loading can be given as [13].

$y(x, t)=T_{1}(t) \sin \left(\pi \frac{x}{l}\right)$

Then the Eq.(12) is written as

$\chi(x, t)=T_{1}(t)\left(\frac{\pi}{l}\right)^{2} \sin \left(\pi \frac{x}{l}\right)$

The strain rate of concrete $\dot{\varepsilon}_{c}(x, t)$ and strain rate of steel $\dot{\varepsilon}_{s}(x, t)$ for arbitrary cross section of RC beams at any time can be obtained according to the linear distribution law of section.

$\dot{\varepsilon}_{c}(x, t)=\phi_{c} \dot{T}_{1}(t)\left(\frac{\pi}{l}\right)^{2} \sin \left(\pi \frac{x}{l}\right) h$

$\dot{\varepsilon}_{s}(x, t)=\phi_{s} \dot{T}_{1}(t)\left(\frac{\pi}{l}\right)^{2} \sin \left(\pi \frac{x}{l}\right)\left(h_{0}-\xi h_{0}\right)$

where, $\phi_{c}, \phi_{s}$ is the strain non-uniformity coefficient of concrete and steel, respectively. $h$ is the distance to neutral axis. $\xi h_{0}$ is the compressive height of concrete, and $\xi$ is the relative height of compressive zone.

The Eq. (15) and Eq. (16) indicate that the strain rates of concrete and steel of RC beam with flexible supports under blast loading involve many factors such as loading characteristic, reinforcement ratio, structure stiffness and supporting conditions.

\section{DYNAMIC INCREASE FACTORS}

The dynamic strengths of concrete or steel are increased as strain rates increased under impact or blast loading. DIF
(Dynamic Increase Factor) is defined as the ratio of dynamic strength to static strength for arbitrary strain rate [10].

The DIF of steel is derived based on $\mathrm{K} \& \mathrm{C}$ model.

$D I F=\left(\frac{\dot{\varepsilon}_{s}}{10^{-4}}\right)^{\alpha}$

where, $\dot{\varepsilon}_{s}$ is the strain rate of steel, and $10^{-4} s^{-1} \leq \dot{\varepsilon}_{s} \leq 255 s^{-1}, \alpha=0.074-0.040 \frac{f_{y}}{414} \cdot f_{y}$ is the yield strength of steel, and $290 \mathrm{MPa} \leq f_{y} \leq 710 \mathrm{MPa}$.

The DIF of concrete is also derived based on $\mathrm{K} \& \mathrm{C}$ model. This model is an improved CEB model, and the DIF of compressive strength is determined by following formulas.

$D I F= \begin{cases}\left(\frac{\dot{\varepsilon}_{c}}{\dot{\varepsilon}_{c s}}\right)^{1.026 \beta} & \left(\dot{\varepsilon}_{c} \leq 30 s^{-1}\right) \\ \gamma\left(\dot{\varepsilon}_{c}\right)^{1 / 3} & \left(\dot{\varepsilon}_{c}>30 s^{-1}\right)\end{cases}$

where, $\quad \dot{\varepsilon}_{c s}=3 \times 10^{-5} s^{-1}$ is the reference strain rate. $\log \gamma=6.156 \beta-0.49, \beta=\left(5+3 f_{c u} / 4\right)^{-1}$ and $f_{c u}$ is the static compressive strength.

\section{EXAMPLES AND DISCUSSIONS}

The blast loads are simplified to uniform triangular loads including rising times. The $\mathrm{RC}$ beam is a rectangular crosssection beam with span of $l=6 \mathrm{~m}$, the section size is $b \times h=0.2 m \times 0.5 m$, and the longitudinal reinforcement ratio is $\rho_{s}=1.2 \%$. The compressive strength of $C 30$ concrete is $f_{c s}=16.5 \mathrm{MPa}$, the elastic modulus is $E_{c}=29.5 \mathrm{GPa}$. The tensile strength of steel is $f_{y}=310 \mathrm{MPa}$, the elastic modulus is $E_{s}=210 G P a$.

\subsection{Influences of Loading Characteristics}

The influences of loading rate $(\Delta p / t)$, blast impulse $(I)$ and overpressure $(\Delta p)$ on strain rates are analyzed with relative stiffness $\xi=e l^{3} / B=200$ and damping coefficient $d=10000 \mathrm{~N} \cdot \mathrm{s} / \mathrm{m}$, where geometric parameters and material properties remain unchanged. It is shown in Figs. (2) and (3) that the strain rate of concrete $\ln \dot{\varepsilon}$ is $0.80,0.81,0.96$, 0.96 , and the strain rate of steel $\ln \dot{\varepsilon}$ is $1.13,1.17,1.43,1.50$ respectively corresponding to four different loading characteristics. It is indicated that the dynamic loading rates have not obvious influences on the values of material strain rates for a given blast impulse $(I)$ and overpressure $(\Delta p)$. The reason is that the blast rising time is very short and the supports are deformable, the materials have not yet deformed fully during blast rising. 


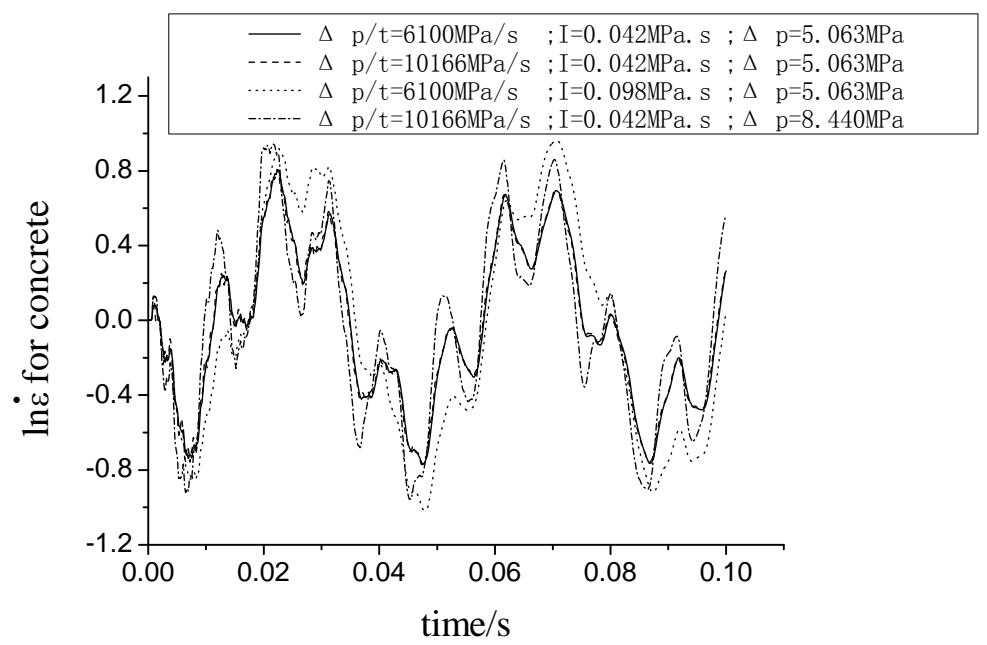

Fig. (2). Variations of strain rate for concrete versus time.

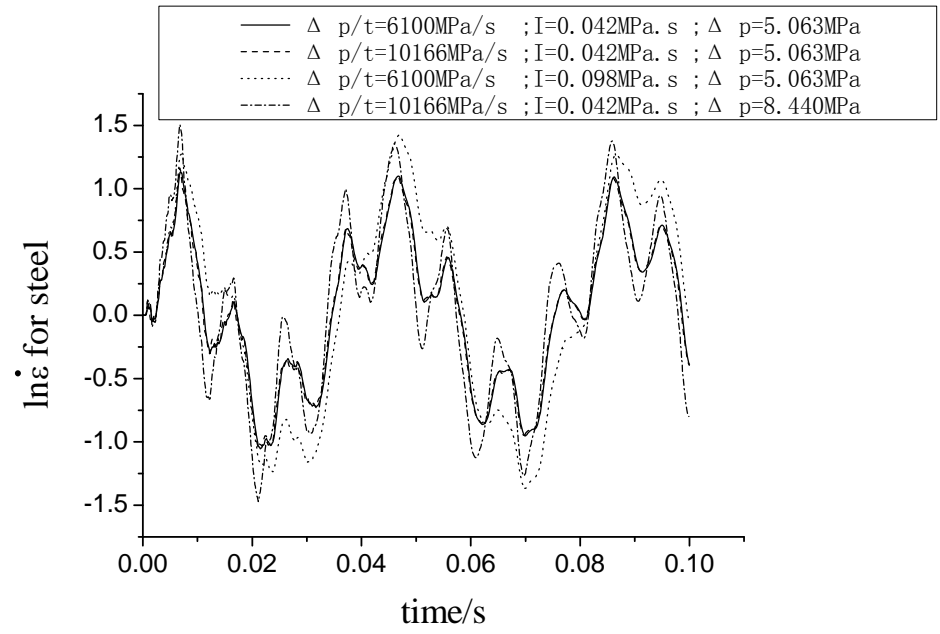

Fig. (3). Variations of strain rate for steel versus time.

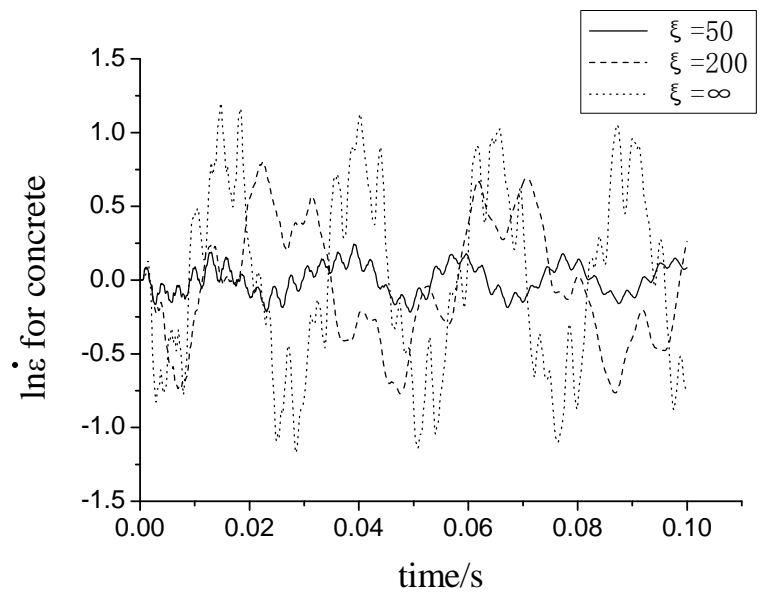

Fig. (4). Variations of strain rate for concrete versus time.

\subsection{Influences of Support Stiffness}

The variations of strain rate versus time are obtained by Eq. (15) and Eq. (16) with loading rate of $6.1 \times 10^{3} \mathrm{MPa} / \mathrm{s}$ and damping coefficient $d=10000 N \cdot s / m$, where geometric

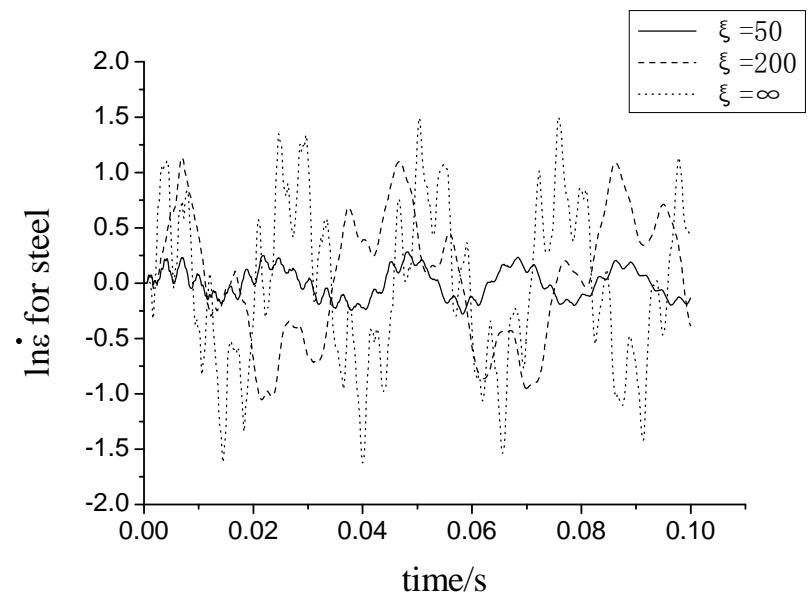

Fig. (5). Variations of strain rate for steel versus time.

parameters and material properties remain unchanged. It is observed in Figs. (4) and (5) that the strain rate of concrete $\ln \dot{\varepsilon}$ is $0.19,0.80,1.20$, and the strain rate of steel $\ln \dot{\varepsilon}$ is $0.23,1.17,1.49$ respectively corresponding to the relative stiffness of 50,200 and $\infty$. It is indicated that the strain rates 


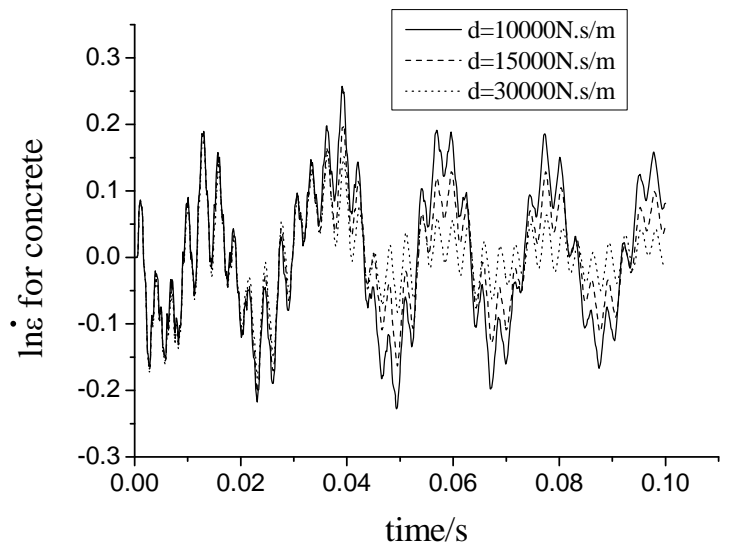

Fig. (6). Variations of strain rate for concrete versus time.

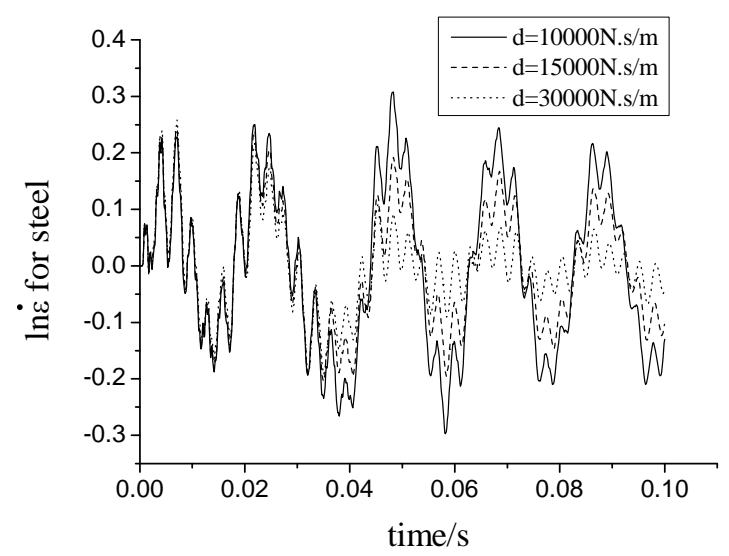

Fig. (7). Variations of strain rate for steel versus time.

of concrete and steel are increased as support stiffness increased, also the vibration frequencies. The maximal values of strain rate are gradually attenuated versus response times. It shows that the deformations of flexible support have buffering effects on the structural deformation as support stiffness is small enough. The larger support stiffness, the higher values of strain rate will be derived.

\subsection{Influences of Support Damping}

The variations of strain rate versus time are obtained by Eq. (15) and Eq. (16) with loading rate of $6.1 \times 10^{3} \mathrm{MPa} / \mathrm{s}$ and relative stiffness of $\xi=e l^{3} / B=50$, where geometric parameters and material properties remain unchanged. It can be observed in Figs. (6) and (7) that the support damping has not any influences on the values of the strain rate during blast loading. The lagged phenomenon of concrete and steel is observed when support damping is small enough, moreover the vibration amplitudes attenuated slowly. It is indicated that the vibration energy of structure is quickly dissipated as support damping increased. The support damping has not obvious influences on the material strain rates during blast loading.

\subsection{Comparison of DIF}

Table $\mathbf{1}$ is the comparison of the results of Ref. [15] and that by the method in this paper. It is summarized in Table $\mathbf{1}$ that the DIF of concretes are significantly higher than that of steel, and it is consistent with actual case. The strain rate effects of concretes and steel are analyzed by the simplified formulas presented in literature [15], in which it is to take the loading rates instead of the strain rates. It is indicated that the analytical results are larger than that by the method in this paper, and it will result in an overestimation of DIF. On the other hand, the larger support stiffness the higher DIF is obtained, and the DIF is higher by $25 \%$ with respect to the analytical results of this paper. Therefore, for the blast-resistant structures with flexible supports it is necessary to estimate the actual strain rate effects by taking loading characteristics, reinforcement ratio and boundary conditions into accounted.

\section{CONCLUSION}

The influence of dynamic characteristics, boundary conditions on the effects of strain rate of concrete and steel for $\mathrm{RC}$ beam with flexible supports under blast loading are theoretically investigated.

(1) The blast loading rates have not any influences on the strain rates of concrete and steel for RC beam with flexible supports, but the values of strain rates are increased obviously as blast impulse $(I)$ and overpressure $(\Delta p)$ increased.

(2) The larger support stiffness the higher vibration frequencies of RC beam with flexible supports obtained, also the maximal values of strain rate.

(3) The lagged phenomenon of concrete and steel occur as support damping is small enough, and the vibration amplitudes attenuated slowly. It is indicated that the vibration energy of structure is quickly dissipated as support damping increased.

(4) Not only the characteristics of blast load, but also the geometric parameters and boundary condition influence

Table 1. Comparisons of maximal DIF.

\begin{tabular}{|c|c|c|c|c|c|c|c|c|c|c|c|}
\hline Ref. [15] & Concrete & 2.06 & 2.12 & 2.06 & 2.12 & 2.06 & 2.06 & 2.06 & 2.06 & 2.06 & 2.06 \\
\hline This paper & Concrete & 1.83 & 1.83 & 1.85 & 1.85 & 1.68 & 1.83 & 1.87 & 1.71 & 1.68 & 1.67 \\
\hline
\end{tabular}


on the material DIF. For the blast-resistant structures with flexible supports it is necessary to derive the actual effects of strain rate by taking loading characteristics, reinforcement ratio and boundary conditions into account.

\section{CONFLICT OF INTEREST}

The authors confirm that this article content has no conflict of interest.

\section{ACKNOWLEDGEMENTS}

The authors gratefully acknowledge the financial support from the National Natural Science Foundation of China (Grant: 51378498), the Natural Science Foundation of Jiangsu province (Grant: BK20141066), and the Open Foundation of State Key Laboratory for GeoMechanics \& Deep Underground Engineering, China University of Mining and Technology (Grant: SKLGDUEK1208).

\section{REFERENCES}

[1] " A Chronology of Significant International Terrorism for 2004", National Counterterrorism Center, US, 2005.

[2] C. Liu, and G. Zheng, "Analysis of the influence of ground unequal settlement on the structure with elastic support model method," Journal of Building Structures, vol. 25, no. 4, pp. 124-128, 2004.

[3] J. Xia, M. C. Zhu, and D. Y. Ma, "Analysis of lateral natural vibration of beams with lumped masses and elastic supports," Mechanics in Engineering, vol. 22, no.5, pp. 27-30, 2002.
[4] L. H. Yan, S. Y. Zeng, and B. Chen, "The dynamic responses of an elastic support beam," Engineering Mechanics, vol. (Supplement), pp. 381-343, 2003.

[5] Q. Fang, and M. L. Du, "Dynamic responses of an elastically supported beam with damping subjected to blast loads," Mechanics in Engineering, vol. 28, no. 2, pp. 53-56, 2006.

[6] W. X. Chen, and Z. K. Guo, "Dynamic responses of reinforced concrete beam with viscous-spring supports subjected to low velocity impact," Engineering Mechanics, vol. 27, no. 5, pp. 115-121, 2010.

[7] Q. Fang, and P. A. Wu, "Main factors affecting failure m odes of blast loaded RC beams," Chinese Journal of Computational Mechanics, vol. 20, no. 1, pp. 39-42, 2003.

[8] J. Ghabossi, W. A. Millavec, and J. Isenberg, "R/C structures under impulsive loading," Journal of Structural Engineering, vol. 110, no. 3, pp. 505-552, 1984.

[9] J. Rosst, "Direct shear failure in reinforced concrete beams under impulsive loading," AFWL-TR-83-84, Kirtland Air Force BASE, NM: Air Force Weapons Laboratory, 1983.

[10] Y. C. Shi, and Z. X. Li, "Dynamic responses and failure modes of RC columns under blast loading," Journal of Building Structure, vol. 29, no. 4, pp. 112-117, 2008.

[11] R. W. Clough, and J. Penzien, "Dynamic of structures (2nd Edition)", Computers and Structures, Inc., Berkeley, USA, 1993.

[12] People's Republic of China National Standard: Code for design of concrete structures (GB 50010-2010). Beijing: China Building Industry Press, 2011, pp. 97-100.

[13] W. B. Sun, B. Wang, and C. Wu, "Study on the strain rates of concrete and steel in concrete beams under blast loadings," Concrete, vol. 12, pp. 35-37, 2008.

[14] M. Y. Wang, D. R. Wang, and C. M. Song, "A calculation method of reinforced concrete beam under low velocity impact," Acta Armamentarii, vol. 27, no. 3, pp. 399-405, 2006.

[15] T. Krauthammer, H. M. Shanaa, and A. Assadi, "Response of structural concrete elements to severe impulsive loads," Computers \& Structures, vol. 53, no.1, pp. 119-130, 1994.

This is an open access article licensed under the terms of the Creative Commons Attribution Non-Commercial License (http://creativecommons.org/licenses/ by-nc/3.0/) which permits unrestricted, non-commercial use, distribution and reproduction in any medium, provided the work is properly cited. 